\section{Indonesian propolis suppressed the expression of COX-2 in inflamed rat dental pulp in direct capping treatment}

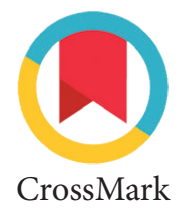

\author{
Ardo Sabir
}

Department of Conservative Dentistry, Faculty of Dentistry, Hasanuddin University, Makassar, Indonesia
*Correspondence to: Ardo Sabir, Department of Conservative, Faculty of Dentistry, Hasanuddin University, Makassar, Indonesia ardo.sabir@yahoo.com

Received: 29 May 2019 Revised: 19 June 2019 Accepted: 25 July 2019 Available Online 1 August 2019

Keywords: Cyclooxygenase-2, Dental pulp, Inflamation, Propolis, Rat

Cite this Article: Sabir A. 2019. Indonesian propolis suppressed the expression of COX-2 in inflamed rat dental pulp in direct capping treatment. Journal of Dentomaxillofacial Science 4(2): 109-113. D0l:10.15562/jdmfs.v4i2.966

\section{Introduction}

Propolis, or bee glue is a sticky, rubbery, brown, thermoplastic resin substance collected by bees from buds and exudates of the plants. ${ }^{1}$ Honey bees use propolis in their hives as a repairing crevice, and as a surface cover, hardener and preservative. Also, it is used as a repellent since it is applied inside the beehive that protect it from insects. ${ }^{2}$ There are a number of studies documenting the biological functions of propolis, its extracts and constituents. ${ }^{3}$ Several phamocological actitivities have been described for propolis, including antibacterial, ${ }^{4}$ anti-inflammatory, ${ }^{5}$ accelerated wound healing ${ }^{6}$ and immunomodulatory. ${ }^{7}$ Among of its constituents, both flavonoid and non-flavonoid substances of propolis also showed anti-bacterial $^{8}$ and anti-inflammatory activities. ${ }^{9}$ The chemical composition of propolis is very complex, depends on the collecting location, time and plant source. ${ }^{10}$ Commonly, the composition of propolis primarily consists of resinous (50\%), wax $(30 \%)$, essential and aromatics oils $(10 \%)$, bee pollen (5\%) and other substances (5\%). ${ }^{11}$

Recently, a new trend of using apitherapy has increased worldwide to treat many diseases. Using propolis in conservative dentistry and endodontic treatment to treat tooth and pulp diseases is a pop- biopsy samples were obtained, processed for immunostaining of COX-2 and viewed under light microscope. Data was statistically analyzed using Friedman and Kruskal-Wallis tests with significant level $\mathrm{P}<0.05$

Results: Except in group I, COX-2 expression was decreased in all treatment group with the longer of observation time periods. In group II and group V, COX-2 expression was weaker than group III and IV at all periods time. However, there was no statistically significant differences of $\mathrm{COX}-2$ expression among groups for each time period.

Conclusion: The present study suggests that EEP and $\mathrm{Ca}(\mathrm{OH}) 2$ were stronger than other materials test to suppressed $\mathrm{COX}-2$ expression on inflamed rat dental pulp. ular practice such as cariostatic agent in supressing cariogenic bacteria, ${ }^{12}$ desensitizing agent to treat hypersensitivity dentin, ${ }^{13}$ intracanal irrigant, ${ }^{14}$ cavity disinfecting agent in atraumatic restorative treatment, ${ }^{15}$ medicament during root canal treatment, ${ }^{16}$ and also as direct pulp capping agent. ${ }^{17}$ Previous studies have demonstrated that propolis is toxic to dental pulp fibroblasts at $2 \mathrm{mg}$ or above ${ }^{18}$ and not reduced the viability of dental pulp fibroblasts at 1 $\mathrm{mg} / \mathrm{mL} .^{19}$

Dental pulp is a loose connective tissue uniquely situated within the rigid encasement of mineralized dentin. However, dental pulp may become exposed due to caries, accidental mechanical during cavity preparation, tooth fracture or attrition ${ }^{20}$ and these can result an inflammation. Prostaglandins (PG) are important mediators of inflammation, the synthesis of which is initiated by release of arachidonic acid from cell membranes. Cyclooxygenases (COX) are enzymes responsible for conversion of arachidonic acids to PG. Two isoforms and one of variant of COX (COX-1, COX-2, and COX-3, respectively) have been cloned and characterized. COX-1 is constitutively expressed in cells and is considered a housekeeping enzyme. ${ }^{21}$ The inflammatory and inducible effects of COX are mediated through COX-2, which is up-regulated in inflamed tissues 
and is at low or undetectable levels in healthy tissues. ${ }^{22}$ COX-2 has been recently shown to play an important role in the pathogenesis of dental pulpal inflammation. ${ }^{23,24}$

Trigona sp was one of honeybee species that we can found in South Sulawesi province, Indonesia. This honeybee species is stingless and can produce a lot of propolis. Recently, propolis been drawn much attention due to its anti-inflammatory properties. However, the potential anti-inflammatory effects of propolis on COX-2 in inflamed dental pulp tissue still remain to be elucidated. Therefore the aim of the present sudy was to analysis COX-2 expression on inflamed rat dental pulp after capped with propolis. The null hypothesis was that apply propolis on inflamed rat dental pulp could be decrease COX-2 expression.

\section{Material and Methods}

The experimental protocol was approved by the ethical committee of Faculty of Medicine, Hasanuddin University. The study was conducted at Bio-Pharmacal Laboratory, Faculty of Pharmacy and The Animal Research Development Center, Faculty of Veterinary Medicine, Gadjah Mada University, Yogyakarta and Department of Pathological Anatomy, Faculty of Medicine, Hasanuddin University, Makassar, Indonesia.

Two hundred and fifty grams raw propolis was obtained from Honey Bee Development Center, Hasanuddin University, Makassar which collected from honeycombs in Luwu regency, South Sulawesi Province, Indonesia. It was sliced and squashed with a mortal and pestle, and the extract was maserated for five days at temperature $45^{\circ} \mathrm{C}$ with continous shaking with low rpm in a flask containing 1.25 L ethyl alcohol (ratio 1:5). Then filtered through Whatman paper No 1, and the extract was dried at temperature $60^{\circ} \mathrm{C}$ using a vacuum rotary evaporator to get Ethanolic Extract of Propolis (EEP). The residue was separated using toluene to get flavonoid and non-flavonoid fraction.

Eighty male Sprague Dawley rats (8-16 weeks old, weight 200-300 g) were used in this study. The animals were feed the standard food and water ad libitum throughout the study. The room was maintain on a $12 \mathrm{~h}$ light-dark schedule at a temperature of $26 \pm 2^{\circ} \mathrm{C}$ and a relative humidity of $60-70 \%$. Rats were divided into five groups randomly, each consisting of 16 animals. Group I as a negative control was not conducted any treatment. Rats in group II, III, IV and $\mathrm{V}$ were anesthetized intramuscularly with ketamine (Ketalar ${ }^{\circledR}$, Pfizer, Ireland) $(65 \mathrm{mg}$ $\mathrm{kg}^{-1}$ body weight) and xylazine-HCl $\left(\mathrm{Xyla}^{\circledR}\right.$,
Interchemie, Netherland) (7 mg kg-1 body weight). Class I cavities (Black's classification) were prepared on the occlusal surface of the permanent maxillary right first molar using a low-speed tapered round diamond bur (Intensiv ${ }^{\circledR}$, Swizerland) (0.84 $\mathrm{mm}$ in diameter). The pulp was then exposed at the cavity floor using a dental explorer (Martin ${ }^{\circledR}$, Germany) (0.35 mm in tip diameter) and allowed in the oral environment for 1 hour. After that, the exposed pulp directly capped with ethanolic extract propolis (EEP) (group II) $(0.5 \mathrm{mg})$, flavonoid propolis (Group III) $(0.5 \mathrm{mg})$, non-flavonoid propolis (group IV) $(0.5 \mathrm{mg})$, or $\mathrm{Ca}(\mathrm{OH})_{2}\left(\mathrm{Hydcal}^{\circledR}, \mathrm{Tech}^{\circledR} \mathrm{w}\right.$, Rio de Janeiro, Brazil) as positive control (group V) $(0.5 \mathrm{mg})$. Cavity was then air-dried and filled with permanent filling material (HS Posterior Extra ${ }^{\circledR}$, GC, Tokyo, Japan).

In each group, 4 rats were sacrificed at 6 hours, 2 days, 4 days and 7 days respectively. The teeth and the surrounding bone were resected, fixed in Bouin's fixative solution for 1 days, decalcified with acetic acid/formal saline for 7 days, embedded in paraffin. Consecutive $6 \mu$ l thick sections were cut with bucco palatal direction using a rotary microtome, and collected on poly-L-lysinecoated slides. Endogenous peroxidase was blocked by incubation in $0.03 \%$ hydrogen peroxide in absolute methanol for 30 minutes at room temperature and washed with phosphate buffer saline. Immunohistochemistry was performed using a primary mouse monoclonal antibody against COX-2 (Neuromics, USA). After 30 minutes of incubation with block solution, sections were incubated with the primary antibodies at temperature $4^{\circ} \mathrm{C}$ overnight, followed by sequential 30 minutes incubations with biotinylated secondary antibody and streptoavidin universal kit (ABC Elite Vectastain, Japan). The sections were counterstained with hematoxylin solution and mounted with glycerol-gelatin and viewed under a light microscopy (Leica ${ }^{\circledR}$, Olympus BX41U-CA, Tokyo, Japan).

The evaluation of COX-2 expression in dental pulp was carried out according to FaleiroRodrigues et al. ${ }^{25}$ based on two parameters: (1). The intensity of COX-2 expression (no detected= 0 ; weak $=1$; moderate $=2$; strong $=3$ ) and (2) precentage of COX-2-positive cells $(0 \%=0 ; 1 \%-10 \%=1$; $11 \%-50 \%=2 ; 51 \%-100 \%=3$ ). The sum of score from both parameter was then grading as following : Score $0=$ grade 0 (weak expression); Score 1-2=grade 1 (weak expression); Score 3-4=grade 2 (moderate expression); Score 5-6=grade 3 (strong expression). The scoring of COX-2 expression on rat dental pulp was blindly investigated by two separate pathologists. If there was any disagree- 
Table 1 The difference grade of COX-2 expression among time periods for each group

\begin{tabular}{lcccccc}
\hline \multirow{2}{*}{ Groups } & \multicolumn{5}{c}{ Mean Rank } & Friedman \\
\cline { 2 - 6 } & 6 hours & 2 days & 4 days & 7 days & Pest \\
\hline Without treatment & 2.50 & 2.50 & 2.50 & 2.50 & 0.00 & 1.00 \\
EEP & 2.75 & 2.63 & 2.63 & 2.55 & 0.09 & 0.96 \\
Flavonoid & 2.90 & 2.85 & 2.80 & 2.77 & 1.92 & 0.99 \\
Non-flavonoid & 3.50 & 3.25 & 3.15 & 3.00 & 3.90 & 0.27 \\
$\mathrm{Ca}(\mathrm{OH})_{2}$ & 2.75 & 2.75 & 2.63 & 2.63 & 1.14 & 0.20 \\
& & & & & & \\
\hline
\end{tabular}

Note: Significant difference at $\mathrm{P}<0.05$

Table 2 The difference grade of COX-2 expression among groups for each time period

\begin{tabular}{lcccccc}
\hline \multirow{2}{*}{ Groups } & \multicolumn{5}{c}{ Mean Rank } & Friedman \\
\cline { 2 - 6 } & 6 hours & 2 days & 4 days & 7 days & test \\
\hline Without treatment & 2.50 & 2.50 & 2.50 & 2.50 & 0.00 & 1.00 \\
EEP & 2.75 & 2.63 & 2.63 & 2.55 & 0.09 & 0.96 \\
Flavonoid & 2.90 & 2.85 & 2.80 & 2.77 & 1.92 & 0.99 \\
Non-flavonoid & 3.50 & 3.25 & 3.15 & 3.00 & 3.90 & 0.27 \\
$\mathrm{Ca}(\mathrm{OH})_{2}$ & 2.75 & 2.75 & 2.63 & 2.63 & 1.14 & 0.20 \\
& & & & & & \\
\hline
\end{tabular}

Note: Significant difference at $\mathrm{P}<0.05$

ment between the evaluators, the sample under discussion was jointly analyzed until a consensus was reached. Statistical package for the social sciences (SPSS Inc. 1989-1999, Chicago, IL, USA) was used for statistical analysis. The Friedman test was used to analysis the significant difference of COX-2 expression between observation time periods for each group. Meanwhile, for analysis the significant difference of COX-2 expression between the groups for each observation time period were carried out by Kruskal-Wallis test. The significant statistical difference was accepted at $\mathrm{P}<0.05$.

\section{Results}

Histogram of COX-2 in rats dental pulp tissue of all groups after 6 hours, 2 days, 4 days and 7 days of application can bee seen at figure 1 . It showed that COX-2 expression was decreased in group II, III, IV and V with the longer observation time periods. Only weak expression of COX-2 showed in group I, II and V at all time periods. In contrast, in group III there was weak and moderate expression of COX-2 at all time periods, while in group IV showed strong expression of COX-2 at 6 hours, 2 days and 4 days. However, the results of Friedman and Kruskal-Wallis tests showed no significant differences $(\mathrm{P}>0.05)$ of COX-2 expression among 4 times periods of each group table 1 and among
5 groups of each time period table 2.

No necrotic pulp tissues were found in all animals of treatment groups throughout the study. The photomicrograph of COX-2 evaluation is presented here in only by the section from all groups at 6 hours and 7 days figure 2.

\section{Discussion}

During tissue growth and inflammation, the level of PG is generated by COX-2. Inflammatory mediators such as interlukin-1 (IL-1), tumor necrosis factor- $\alpha$ (TNF- $\alpha$ ), growth factor, lipopolysaccharide and tumor cells are stimulators of the COX-2 expression. ${ }^{26}$ Many pathological cytokines, such as IL- 1 and TNF- $\alpha$, stimulate COX-2 mRNA expression and PGE-2 production, which lead to tissue destruction. ${ }^{27}$ It has been reported that PGE-2 might be involved in pathogenesis of pulpal inflamation ${ }^{28}$ because implicated in many inflammation processes, such as vasodilation, increased vascular permeability, chemotaxis and pain. ${ }^{23}$ Therefore, it can be used as an indicaor of the severity of pulpal inflamation. COX-2 participates in the pathogenesis of pulpal inflammation. ${ }^{26}$ Inflamed pulp, fibroblast and macrophages expressed COX-2, leading to PGE-2 production. ${ }^{23}$ Study by holt, Hutchins and pileggi ${ }^{22}$ found the up-regulated of COX-2 on inflamed dental pulp and low or undetectable levels on healthy dental pulp. In the specimen of radicular cyst, COX-2 level was found also high. ${ }^{29}$

Anti-inflammatory and immunomodulatory activities of propolis and its constituents have been study by a number of researchers. The result of present study demonstrated that the expression of COX-2 was decreased after EEP, flavonoid propolis, non-flavonoid propolis and $\mathrm{Ca}(\mathrm{OH})_{2}$ application on inflamed dental pulp with the longer observation time periods. However, the COX-2 expression after EEP and $\mathrm{Ca}(\mathrm{OH})_{2}$ application weaker than flavonoid propolis and non-flavonoid propolis application. Our previous study also found the suppession dental pulp inflammation by propolis. ${ }^{9}$

Propolis was known to have anti-inflammatory, anti bacterial, anti oxidative, and immunomodulatory activity that permit inhibition of COX-2 expression, ${ }^{30}$ perhaps via suppression of cytokines production $^{31}$ macrophages-derived nitric oxide. Considering that propolis is a complex mixture, synergistic interactions between its compounds must also be considered as an important factor in its anti-inflammatory activity. The anti-inflammatory activity of propolis not only depends on the presences of flavonoids and caffeic acid 


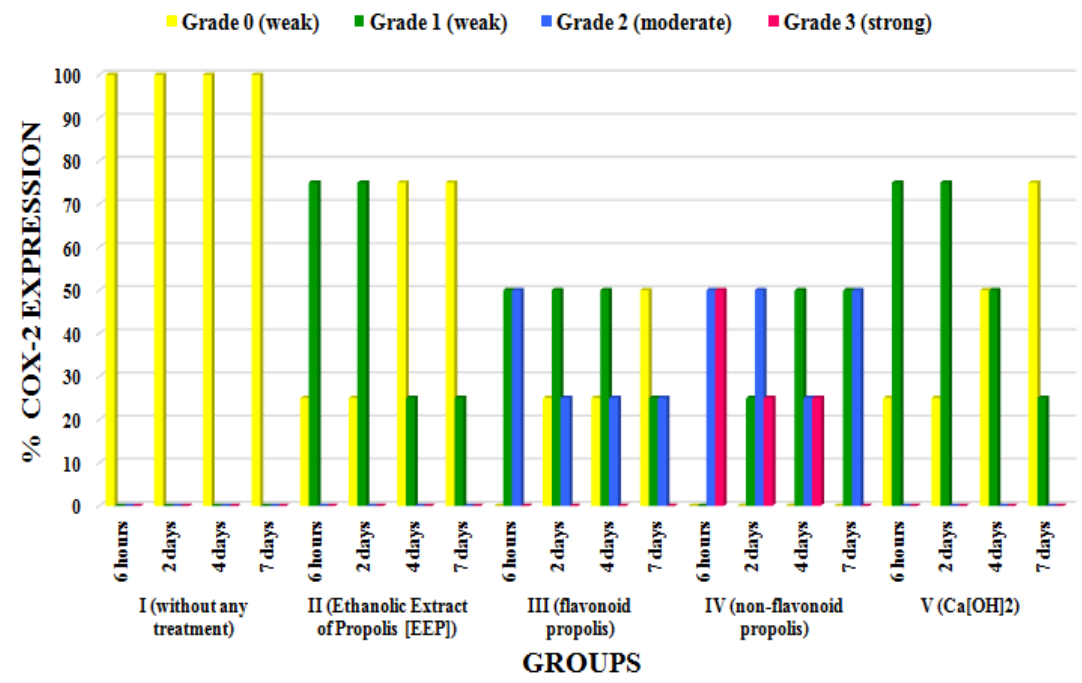

Figure 1 Histogram of percentage of COX-2 expression on inflamed rat dental pulp of all groups after 6 hours, 2 days, 4 days and 7 days application of materials test
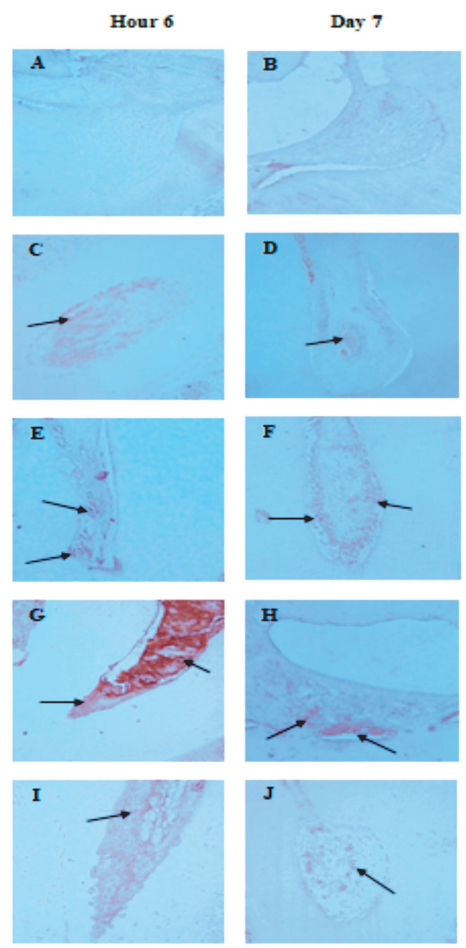

Figure 2 The expression of COX-2 on inflamed rat dental pulp after materials test application for 6 hours and 7 days. Dental pulp without any treatment (negative control) in groups I (A[weak]$\mathrm{B}[$ weak]) and exposed dental pulp in groups II (C[weak] $\mathrm{D}$ [weak]), III (E[moderate]-F[moderate]), IV (G[strong]$\mathrm{H}[$ moderate $]$ ) and $\mathrm{V}$ (I[weak]-J[weak]), capped with ethanolic extract of propolis (EEP), flavonoid propolis, non-flavonoid propolis and $\mathrm{Ca}(\mathrm{OH})_{2}$ respectively. Arrows show cells with positive COX-2 expression. Immunohistochemistry method, DAB chromogen, Original magnification 200x and caffeic acid phenethyl ester (CAPE), but also by addictional active compounds such as ferulic acid, (hydroxyl) cinnamic acid and diterpene derivates. ${ }^{32}$ Previosly study by Rossi et al. ${ }^{33}$ found that EEP, flavonoid (galangin) and non-flavonoid (CAPE) propolis were effective to inhibit COX-2 activity in macrophages but not to other non-flavonoid propolis substances (caffeic, ferulis, cinnamic and chlorogenic acids).

Presently, $\mathrm{Ca}(\mathrm{OH})_{2}$ was used in this study as material of control positive group because until now it was known as the most promising capping agent for direct pulp capping treatment to preserve tooth vitality in an exposed pulp cavity. The weak expression of COX-2 on inflamed rat dental pulp caused due to its alkanity. This alkanity actually has a beneficial effect on the injured dental pulp tissue, insofar as it causes mild irritation and stimulates the conjunctive tissue to defend and repair itself, initiating an mild inflammatory reaction to control and eliminate the irritating agent. ${ }^{34}$ Study by NelsonFilho et al. ${ }^{35}$ found that $\mathrm{Ca}(\mathrm{OH})_{2}$ induces a lesser degree of inflammatory infiltrate in the initial hours and inducing subsequent tissue repairing.

\section{Conclusion}

This present study showed that the application of all material test on inflamed rats dental pulp tissue decreased COX-2 expression along with the increase of the observation time period duration. However, EEP has better effect than flavonoid propolis, nonflavonoid propolis and $\mathrm{Ca}(\mathrm{OH})_{2}$ to decreased $\mathrm{COX}-2$ expression on inflamed rats dental pulp tissue. Therefore, the present results suggest that ethanolic extract of propolis (EEP) as well as $\mathrm{Ca}(\mathrm{OH})_{2}$ suppressed COX-2 expression on inflamed rat dental pulp.

\section{Acknowledgment}

The authors wish to thank Prof. S Pramono, Ph.D (Faculty of Pharmacy, Gadjah Mada University, Yogyakarta, Indonesia) for his technical assistance in propolis preparation.

\section{Conflict of Interest}

The authors report no conflict of interest.

\section{References}

1. Kuropatnicki AK, Szliszka E, Krol W. Historical aspects of propolis research in modern times. Evid Based Complement Alternat Med 2013;2013: 964149. 
2. Simone-Finstrom M, Borba RS, Wilson M, et al. Propolis counteracts some threats to honey bee health. Insects 2017;8: E46.

3. Pietta PG, Gardana C, Pietta AM. Analytical methods for quality control of propolis. Fitoterapia. 2002;73:S7-20.

4. Sforcin JM, Fernandes A Jr, Lopes CA, et al. Seasonal effect on Brazilian propolis antibacterial activity. J Ethnopharmacol 2000;73: 243-249.

5. Wang K, Zhang J, Ping S, et al. Anti-inflammatory effects of ethanol extracts of Chinese propolis and buds from poplar (Populus $\mathrm{x}$ canadensis). J Ethnopharmacol 2014;155: 300-311.

6. Sabir A, Mooduto L, Kaelan C, et al. Impact of the use of ethanolic extract of propolis, flavonoid and nonflavonoid propolis for direct pulp capping in collagen type I density. Braz J Oral Sci 2016;15: 264-268.

7. Sforcin JM. Propolis and the immune system: a review. J Ethnopharmacol 2007;113: 1-14.

8. Veloz JJ, Saavedra N, Alvear M, et al. Polyphenol-rich extract from propolis reduces the expression and activity of Streptococcus mutans glucosyltransferases at subinhibitory concentrations. Biomed Res Int 2016;2016: 4302706.

9. Sabir A, Tabbu CR, Agustiono P, et al. Histological analysis of rat dental pulp tissue capped with propolis. J Oral Sci 2005;47: 135-138.

10. Toreti VC, Sato HH, Pastore GM, et al. Recent progress of propolis for its biological and chemical compositions and its botanical origin. Evid Based Complement Alternat Med 2013;2013: 697390.

11. Huang $\mathrm{S}$, Zhang $\mathrm{CP}$, Wang $\mathrm{K}$, et al. Recent advances in the chemical composition of propolis. Molecules 2014;19: 19610-19632.

12. Anauate NC, Marcucci MC, Paulino N, et al. Effects of typified propolis on mutans streptococci and lactobacilli: a randomized clinical trial. Braz Dent Sci 2013;16: 31-36.

13. Purra AR, Mushtaq M, Acharya SR, et al. A comparative evaluation of propolis and $5.0 \%$ potassium nitrate as a dentine desensitizer: a clinical study. J Indian Soc Periodontol 2014;18: 466-471.

14. Bhardwaj A, Velmurugan N, Sumitha, et al. Efficacy of passive ultrasonic irrigation with natural irrigants (morinda citrifolia juice, aloe vera and propolis) in comparison with $1 \%$ sodium hypochlorite for removal of E. faecalis biofilm: An in vitro study. Indian J Dent Res 2013;24: 35-41.

15. Prabhakar AR, Karuna YM, Yavagal C, et al. Cavity disinfection in minimally invasive dentistry-comparative evaluation of Aloe vera and propolis: a randomized clinical trial. Contemp Clin Dent 2015;6: S24-31.

16. Bazvand L, Aminozarbian MG, Farhad A, et al. Antibacterial effect of triantibiotic mixture, chlorhexidine gel, and two natural materials propolis and aloe vera against enterococcus faecalis: an ex vivo study. Dent Res J (Isfahan) 2014;11: 469-474.

17. Parolia A, Kundabala M, Rao NN, et al. A comparative histological analysis of human pulp following direct pulp capping with propolis, mineral trioxide aggregate and Dycal. Aust Dent J 2010;55: 59-64.

18. Al-Shaher A, Wallace J, Agarwal S, et al. Effect of propolis on human fibroblasts from the pulp and periodontal ligament. J Endod 2004;30: 359-361.

19. Zare JM, Ranjbarian P, Shiravi S. Cytotoxicity evaluation of Iranian propolis and calcium hydroxide on dental pulp fibroblasts. J Dent Res Dent Clin Dent Prospects 2014;8: 130-133.
20. Mejàre IA, Axelsson S, Davidson $\mathrm{T}$, et al. Diagnosis of the condition of the dental pulp: a systemic review. Int Endod J 2012;45: 597-613.

21. Needleman P, Turk J, Jakschik BA, et al. Arachidonic acid metabolism. Annu Rev Biochem 1986;55: 69-102.

22. Holt CI, Hutchins MO, Pileggi R. A real time quantitative PCR analysis and correlation of COX-1 and COX-2 enzymes in inflamed dental pulps following administration of three different NSAIDs. J Endod. 2005;31:799-804.

23. Nakanishi T, Shimizu H, Hosokawa $Y$, et al. An immunohistological study on cyclooxygenase-2 in human dental pulp. J Endod 2001;27: 385-388.

24. Güven G, Altun C, Günhan Ö, et al. Co-expression of cyclooxygenase- 2 and vascular endothelial growth factor in inflamed human pulp: an immunohistochemical study. J Endod. 2007;33: 18-20.

25. Faleiro-Rodrigues C, Macedo-Pinto I, Pereira D, et al. Association of E-cadherin and beta-catenin immunoexpression with clinicopathologic features in primary ovarian carcinomas. Hum Pathol 2004;35: 663-669.

26. Chang YC, Yang SF, Huang FM, et al. Proinflammatory cytokines induce cyclooxygenase-2 mRNA and protein expression in human pulp cell cultures. J Endod 2003;29: 201-204.

27. Chang MC, Chen YJ, Tai TF, et al. Cytokine-induced prostaglandin E2 production and cyclooxygenase-2 expression in dental pulp cells: downstream calcium signaling via activation of prostaglandin EP receptor. Int Endod J 2006;39: 819-826.

28. Lin SK, Kuo MY, Wang JS, et al. Differential regulation of interleukin-6 and inducible cyclooxygenase gene expression by cytokines through prostaglandin-dependent and-independent mechanisms in human dental pulp fibroblasts. J Endod 2002;28: 197-201.

29. Tsai CH, Huang FM, Yang LC, et al. Immunohistochemical localization of cyclooxygenase-2 in radicular cysts. Int Endod J 2002;35: 854-858.

30. Paulino M, Alvareda E, Iribarne F, et al. Toward the understanding of the molecular basis for the inhibition of COX-1 and COX-2 by phenolic compounds present in Uruguayan propolis and grape pomace. J Biomol Struct Dyn 2016;34: 2643-2657.

31. Sabir A, Sumidarti A. Interleukin-6 expression on inflamed rat dental pulp tissue after capped with Trigona sp. propolis from South Sulawesi, Indonesia. Saudi J Biol Sci 2017; 24: 1034-1037.

32. Chirumbolo S. Anti-inflammatory property of propolis. J Clin Biochem Nutr 2015;56: 163-164.

33. Rossi A, Ligresti A, Longo R, et al. The inhibitory effect of propolis and caffeic acid phenethyl ester on cyclooxygenase activity in J774 macrophages. Phytomedicine 2002;9: 530-535.

34. Fransson H. On the repair of the dentine barrier. Swed Dent J Suppl 2012;226: 9-84.

35. Nelson-Filho P, Silva LA, Leonardo MR, et al. Connective tissue responses to calcium hydroxide-based root canal medicaments. Int Endod J 1999;32: 303-311.

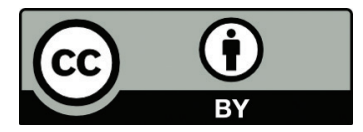

This work is licensed under a Creative Commons Attribution 